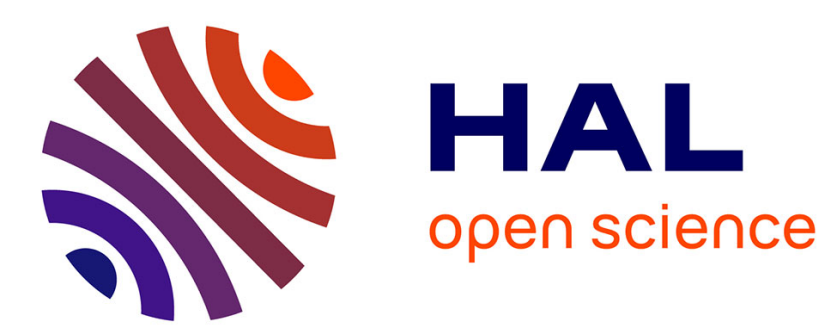

\title{
Easy Access To Allylic Sulfones Through Transition Metal-Free Hydrosulfonylation Of Allenes
} Lucas Pagès, Sébastien Lemouzy, Marc Taillefer, Florian Monnier

\section{To cite this version:}

Lucas Pagès, Sébastien Lemouzy, Marc Taillefer, Florian Monnier. Easy Access To Allylic Sulfones Through Transition Metal-Free Hydrosulfonylation Of Allenes. Journal of Organic Chemistry, 2021, 86 (21), pp.15695-15701. 10.1021/acs.joc.1c01345 . hal-03455769

\section{HAL Id: hal-03455769 https://hal.science/hal-03455769}

Submitted on 29 Nov 2021

HAL is a multi-disciplinary open access archive for the deposit and dissemination of scientific research documents, whether they are published or not. The documents may come from teaching and research institutions in France or abroad, or from public or private research centers.
L'archive ouverte pluridisciplinaire HAL, est destinée au dépôt et à la diffusion de documents scientifiques de niveau recherche, publiés ou non, émanant des établissements d'enseignement et de recherche français ou étrangers, des laboratoires publics ou privés. 


\title{
Easy Access To Allylic Sulfones Through Transition Metal-Free Hy- drosulfonylation Of Allenes.
}

\author{
Lucas Pagès, ${ }^{\dagger}$ Sébastien Lemouzy, ${ }^{\dagger}$ Marc Taillefer,${ }^{\dagger *}$ and Florian Monnier ${ }^{\dagger,} \neq *$
}

${ }^{\dagger}$ ICGM, Univ Montpellier, CNRS, ENSCM, Montpellier, France, 240 Avenue du Professeur Emile JEANBRAU - 34296 Montpellier (France)

‡Institut Universitaire de France (IUF), 1 Rue DESCARTES, Paris 75231 Cedex 5, France.

Supporting Information Placeholder

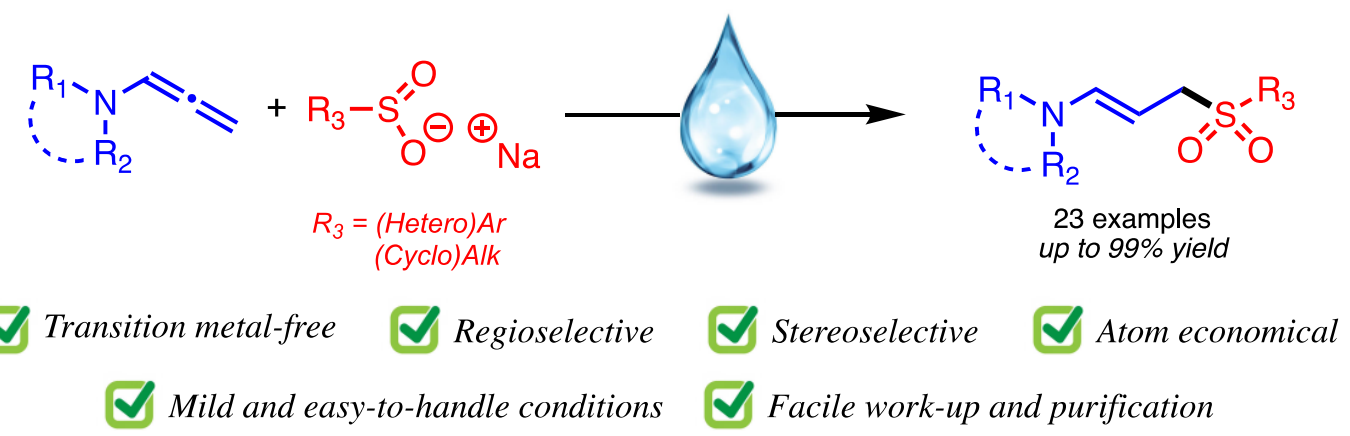

ABSTRACT: A Brønsted acid-mediated addition of (hetero)aryl and (cyclo)alkyl sodium sulfinates to $N$-allenyl deriva-
tives, which proceeds in water, is described under very smooth conditions. This reaction provided a practical and efficient
protocol for the regio- and stereoselective synthesis of allylic sulfones in an atom- and step-economic fashion.

Allylic sulfones are highly valuable structures commonly found in bioactive molecules for pharmaceutical or agrochemical use. ${ }^{1-7}$ They can also be useful intermediates to variously functionalized compounds, either through the $\mathrm{C}\left(\mathrm{sp}^{2}\right)-\mathrm{C}\left(\mathrm{sp}^{2}\right)$ bond or the carbon atom adjacent to the sulfone group. ${ }^{8-10}$ The $\mathrm{SO}_{2}$ moiety is classically introduced either through in situ oxidation of sulfides ( $\mathrm{S}^{\mathrm{II}}$ ) or sulfoxides $\left(\mathrm{S}^{\mathrm{IV}}\right)$ or the use of pre-oxidized sulfur-based reagents $\left(\mathrm{S}^{\mathrm{VI}}\right)$ i.e. sulfinic acid derivatives and their salts, in substitution or cross-coupling reactions (Scheme 1, A).

Allenes are interesting precursors of these allylic structures via hydrofunctionalization ${ }^{11}$ with hydrothiolation followed by in situ oxidation or with direct hydrosulfonylation. The first allene hydrosulfonylation strategies were based on the use of sulfonylhydrazines as a source of sulfone. They can be catalyzed by a palladium/diphosphine system (Yamamoto, ${ }^{12}$ Scheme 1 , eq 1) or by a Rhodium/DPEPhos system (Breit, ${ }^{13}$ Scheme 1, eq 2), occurring respectively on the distal and the proximal carbon of the allene. These methods require the presence of a Brønsted acid in at least stoichiometric quantity, and the use of an organic solvent under moderately high temperature $\left(70^{\circ} \mathrm{C}-80^{\circ} \mathrm{C}\right)$. Breit's group also developed an asymmetric rhodium-catalyzed hydrothiolation of terminal allenes followed by oxidation to afford the chiral branched allylic sulfones in a two-step process (Scheme 1, eq 3). ${ }^{14}$ Over the last years, two transition metal-free allene hydrosulfonylation methods have been described. In 2016, Miao, Ren and coworkers reported a transition metal-free tunable hydrosulfonylation of 3cyclopropylideneprop-2-en-1-ones using sodium sulfinates in the presence of acetic acid affording the corresponding allylic sulfone ( $\gamma$-adduct) in $\mathrm{DMSO}^{15}$ (Scheme 1, eq 4). Very recently, the group of Loh reported a transition-metal catalyst-free regioselective Michael addition of sulfinic acids to $\alpha$-ketoallenes in a mixture of water and ethanol as a solvent, affording the corresponding vinylic sulfone $^{16}$ (Scheme 1, eq 5). This method requires the synthesis of sulfinic acids in one to two steps, either from sodium sulfinate or sulfonyl chloride. ${ }^{17}$ 
Scheme 1. Metal-catalyzed or metal-free hydrosulfonylation of allenes: known methods and novel pathway described herein with TFA.

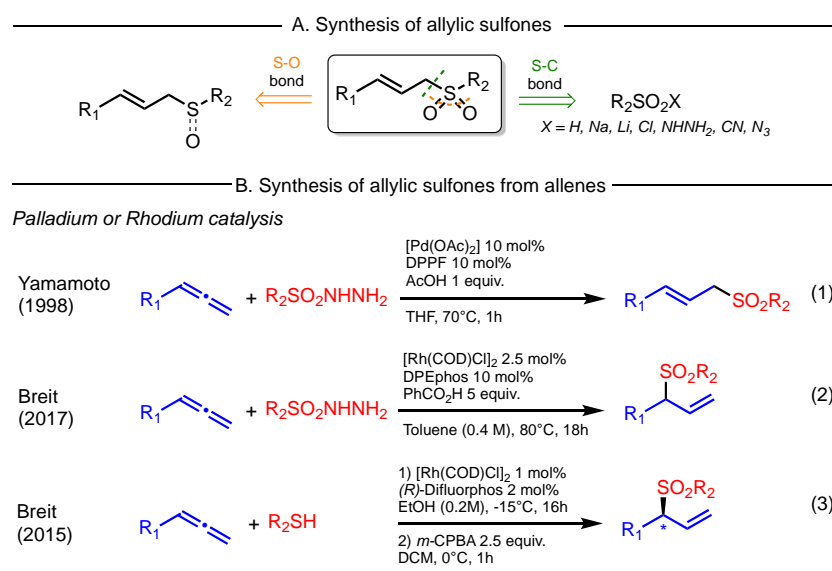

Transition metal-free reaction

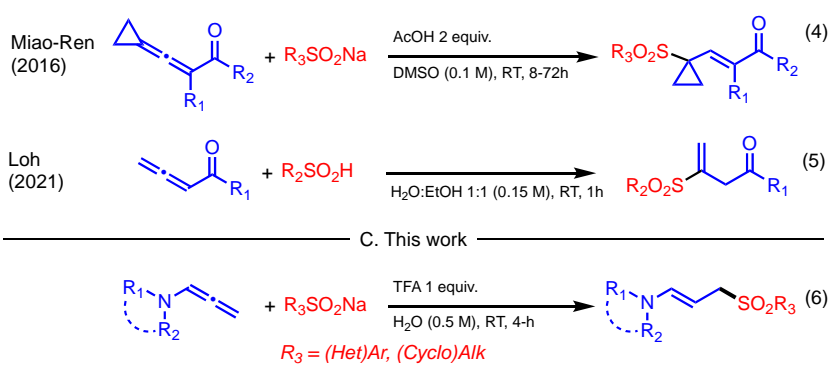

In our course to build new original allylic structures, we started to investigate the C-S bond formation via coppercatalyzed hydrofunctionalization of allenes. After starting with usual conditions described in our previous work for the $\mathrm{C}-\mathrm{C},{ }^{18-20} \mathrm{C}-\mathrm{N}^{21-24}$ and $\mathrm{C}-\mathrm{O}^{25}$ bonds formation, we quickly realized that the reaction could occur without a transition metal, in the presence of a Brønsted acid and under very smooth and easy-to-handle conditions. We herein describe an efficient synthesis of allylic sulfones and 1,3-disulfones through regio- and stereoselective mono and double addition of various (hetero)aryl and (cyclo)alkyl sodium sulfinates to $\mathrm{N}$-allenyl derivatives in aqueous conditions and at room temperature in the presence of trifluoroacetic acid (TFA).

Based on our previous works, we began to study the model reaction between $N$-allenyl-2-pyrrolidinone $\mathbf{1 a}$ and benzene sulfinic acid sodium salt $2 \mathbf{2 a}$ under our $\mathrm{Cu}\left(\mathrm{CH}_{3} \mathrm{CN}\right)_{4} \mathrm{PF}_{6}$-catalyzed system (Table 1). With an acid source we showed that the presence of catalytic amount of copper allows the formation of $50 \%$ of zaa (entry 2, Table 1). Different ligands were associated to copper but no real improvement was detected (entries 3-5, Table 1 ). In the next set of experiments we tested different sources of acid (entries 6-8, Table 1) and we defined trifluoroacetic acid (TFA) as the best one. However in the absence of the copper system, we surprisingly observed that zaa could be obtained in total conversion with 90\% yield (entry 9, Table 1).
Table 1. Copper-catalyzed hydrosulfonylation of 1a with $2 a$ : selected data for reaction parametric study. ${ }^{a}$

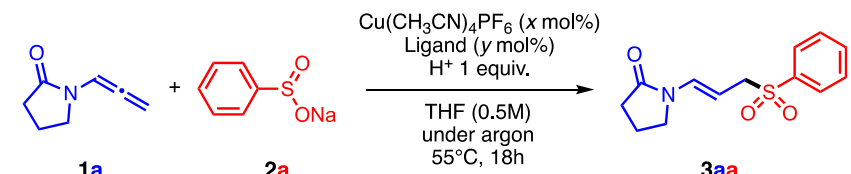

\begin{tabular}{|c|c|c|c|c|c|c|}
\hline & & & $\mathrm{a}$ & & заa & \\
\hline Entry & $x$ & $\mathrm{y}$ & Ligand $^{d}$ & $\mathrm{H}^{+}$source & $\begin{array}{l}\text { Conver- } \\
\text { sion } \\
(\%)^{b, c}\end{array}$ & $\begin{array}{l}\text { Yield } \\
(\%)^{c}\end{array}$ \\
\hline 1 & o & o & - & none & - & - \\
\hline 2 & 10 & o & - & $\begin{array}{l}p \text {-toluic } \\
\text { acid }\end{array}$ & $63 \%$ & $50 \%$ \\
\hline 3 & 10 & 10 & Bpy & $\begin{array}{l}p \text {-toluic } \\
\text { acid }\end{array}$ & $86 \%$ & $57 \%$ \\
\hline 4 & 10 & 10 & Phen & $\begin{array}{l}p \text {-toluic } \\
\text { acid }\end{array}$ & $74 \%$ & $33 \%$ \\
\hline 5 & 10 & 10 & TMEDA & $\begin{array}{l}p \text {-toluic } \\
\text { acid }\end{array}$ & $95 \%$ & $51 \%$ \\
\hline 6 & 10 & 10 & Bpy & TMBA & $79 \%$ & $39 \%$ \\
\hline 7 & 10 & 10 & Bpy & PTSA & $76 \%$ & $30 \%$ \\
\hline 8 & 10 & 10 & Bpy & TFA & $>99 \%$ & $58 \%$ \\
\hline 9 & o & o & - & TFA & $>99 \%$ & $90 \%$ \\
\hline
\end{tabular}

a Reaction conditions: 1a ( $0.25 \mathrm{mmol})$, 2 a (2 equiv., $0.5 \mathrm{mmol}$ ), $\mathrm{H}^{+}$source (1 equiv.). Catalyst and ligand were placed in a Schlenk tube under argon in $0.5 \mathrm{~mL}$ of THF (0.5M) for 18 hours at $55^{\circ} \mathrm{C}$. b Based on recovered starting material 1a. ${ }^{\mathrm{c}}$ Determined through ${ }^{1} \mathrm{H}$ NMR analysis using trichloroethylene (1 equiv., 0.25 mmol) as internal standard. d TMBA $=2,4,6$-trimethylbenzoic acid. PTSA $=p$-toluenesulfonic acid. Bpy $=$ 2,2'-bipyridine. Phen $=1,10$-phenantroline. TMEDA $=N, N, N^{\prime}, N^{\prime}-$ tetramethylethylenediamine.

As above mentioned in table 1, best conditions were based on the use of only 1 equivalent of TFA in the absence of the copper catalyst. Hence, we opted to explore milder conditions (Table 2) and were finally able to perform the reaction in water, under open air at room temperature. Thanks to these improved system we could reach the target product zaa in a better yield (from 90\% up to quantitative yield).

Table 2. Acid-mediated hydrosulfonylation of ra with 2a : Selected data for reaction parametric study. ${ }^{a}$

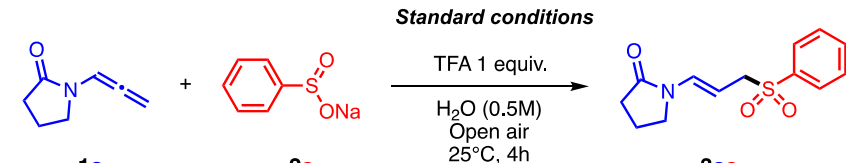

\begin{tabular}{llll}
\multicolumn{1}{c}{$\mathbf{1 a}$} & \multicolumn{1}{c}{$\mathbf{2 a}$} & \multicolumn{2}{c}{ 3aa } \\
\hline \multirow{2}{*}{ Entry } & $\begin{array}{l}\mathrm{C}^{\circ} \mathrm{C}, 4 \mathrm{~h} \\
\text { Variations } \\
\text { from the standard conditions }\end{array}$ & $\begin{array}{l}\text { Conver- } \\
\text { sion } \\
(\%)^{\mathrm{b}, \mathrm{c}}\end{array}$ & $\begin{array}{l}\text { Yield } \\
(\%)^{\mathrm{c}}\end{array}$ \\
\hline $\mathbf{1}$ & THF, instead of $\mathrm{H}_{2} \mathrm{O}$ & $>99 \%$ & $80 \%$ \\
$\mathbf{2}$ & under argon, instead of open air & $>99 \%$ & $90 \%$
\end{tabular}




\begin{tabular}{llll}
3 & $55^{\circ} \mathrm{C}$, instead of $25^{\circ} \mathrm{C}$ & $>99 \%$ & $96 \%$ \\
4 & no TFA & $66 \%$ & o \\
5 & none & $>99 \%$ & $>99 \%$ \\
\hline
\end{tabular}

a Reaction conditions: $1 \mathrm{a}$ ( $0.25 \mathrm{mmol})$, 2 a (2 equiv., $0.5 \mathrm{mmol})$ and TFA (1 equiv., $0.25 \mathrm{mmol}$ ) were placed in a tube under open air in $0.5 \mathrm{~mL}$ of solvent $(0.5 \mathrm{M})$ for 4 hours at $25^{\circ} \mathrm{C}$. b Based on recovered starting material. ${ }^{c}$ Determined through ${ }^{1} \mathrm{H}$ NMR analysis using trichloroethylene (1 equiv., $0.25 \mathrm{mmol}$ ) as internal standard.

With these optimized conditions in hand, we first explored the scope of the method for the hydrosulfonylation of $N$-allenyl-2-pyrrolidinone ra with various readily available (hetero)aryl and (cyclo)alkyl sodium sulfinates compounds 2a-o (Scheme 2). Different para-substituted benzene sodium sulfinates were tested, such as sodium $p$ toluenesulfinate $\mathbf{2 b}, 4$-fluoro and 4-chlorobenzenesulfinic acid $\mathbf{2 c}$ and $\mathbf{2 d}$, and afforded the corresponding products 3ab to 3 ad in high yields (85-91\%). Meta substituted aryl sulfinates partners, 3-chloro 4-methyl benzenesulfinic acid sodium salt 2e and 3(trifluoromethyl)benzenesulfinic acid sodium salt 2 f were also successfully engaged in the reaction and gave corresponding products in $80-89 \%$ yields. Finally, N- and Sheteroaromatics $\mathbf{2 g}$ and $\mathbf{2 h}$ provided the desired products $3 a g$ and 3 ah in good to high yields (6o-83\%). Alkyl sulfinates were then investigated, and both linear (2i, 2j) and cyclic (2k, 2l) derivatives yielded the hydrosulfonylation products, in good isolated yields (61-75\%). Functionalized sulfinates such as sodium triflinate $\mathbf{2 m}$ and sodium 1methyl 3-sulfinopropanoate $\mathbf{2 n}$ were also able to provide the allylic sulfones in good yields $(70-73 \%)$, showing the high tolerance of the process. To prove the robustness of the reaction, we were interested in performing it on a larger scale. The reaction between our model substrates 1a and $2 \mathbf{a}$ was then conducted on a $\mathbf{2} \mathrm{mmol}$ scale, i.e. on a scale eight times larger than usual, and afforded the corresponding hydrosulfonylation product 3aa with a $97 \%$ isolated yield.

Interestingly, we also performed a one-step double hydrosulfonylation of $\mathbf{1 a}$ with $\mathbf{2 a}$ to obtain the corresponding 1,3-disulfone 4aa in high yield. It is noteworthy to mention that the same 1,3-disulfone 4 aa can also be obtained through the hydrosulfonylation of 3aa, demonstrating that our reaction can be applied both to $N$-allenyl and $N$-alkenyl derivatives.
Scheme 2. TFA-mediated hydrosulfonylation of allene ra with various sodium sulfinates $2 a-n$.

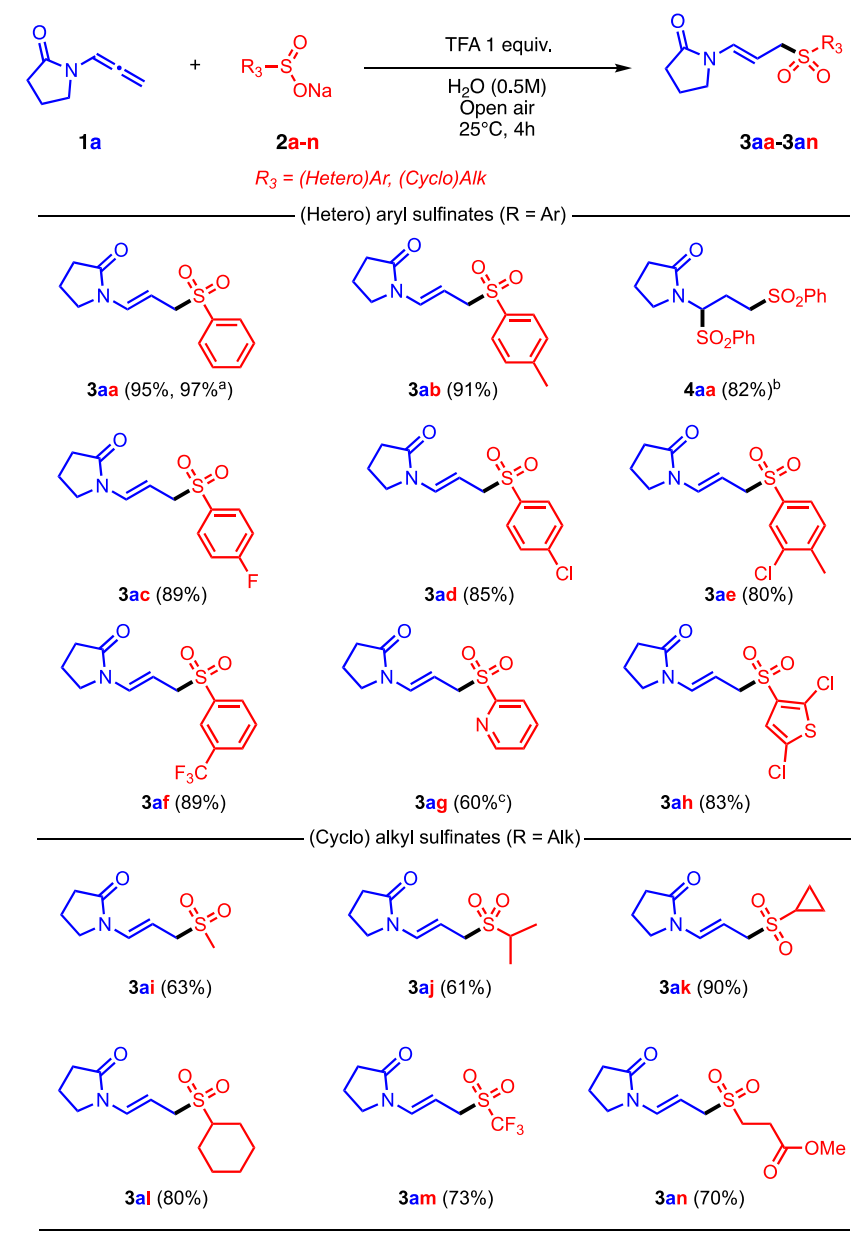

Reaction conditions: 1a ( $0.25 \mathrm{mmol})$, 2a-n (2 equiv., 0.5 mmol), TFA (1 equiv., $0.25 \mathrm{mmol}$ ), $\mathrm{H}_{2} \mathrm{O}$ (0.5M, $0.5 \mathrm{~mL}$ ), open air, $25^{\circ} \mathrm{C}, 4 \mathrm{~h}$. Isolated yields. a The reaction was performed on a $2 \mathrm{mmol}$ scale. ${ }^{\mathrm{b}}$ The reaction was performed at $40^{\circ} \mathrm{C}$ over two days under open air with 4 equiv. of TFA, 4 equiv. of $\mathrm{PhSO}_{2} \mathrm{Na}$ and $\mathrm{H}_{2} \mathrm{O} / \mathrm{THF}$ 1:1 (o.25M) as the solvent. " The reaction was performed with 2 equiv. of TFA.

We then explored the reactivity of different $N$-allenyl derivatives with several (hetero)aryl and (cyclo)alkyl sodium sulfinates (Scheme 3). The N-allenyl-2oxazolidinone $\mathbf{1 b}$ was successfully involved in the reaction, affording both aryl and alkyl allylic sulfones in medium to excellent yields (51-90\%). The symmetrical diallene $N, N$-diallenyl-2-imidazolidinone 1c afforded the corresponding double hydrosulfonylation product 3ca in $60 \%$ yield when a mixture $1: 1$ of water and THF was used as solvent. We also investigated the reactivity of $N$ sulfonyl allenamides, and observed that these substrates and their corresponding hydrofunctionalization products are sensitive under our acidic conditions. Nevertheless, the sulfones $\mathbf{3 d a}$ and $\mathbf{3} \mathbf{d b}$ were obtained in moderate to good isolated yields (35-6o\%). 
Scheme 3. TFA-mediated hydrosulfonylation of various allenyl derivatives with different sodium sulfinates.

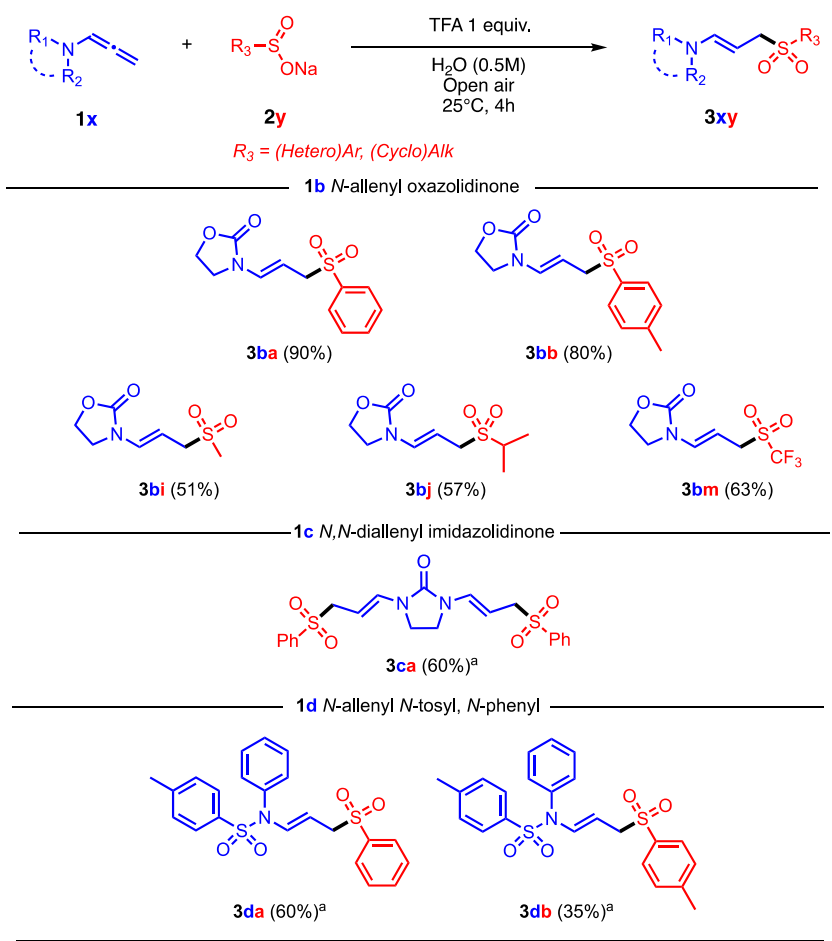

Reaction conditions (unless otherwise mentionned): 1 (o.25 mmol), 2 (2 equiv., $0.5 \mathrm{mmol}$ ), TFA (1 equiv., $0.25 \mathrm{mmol}$ ), $\mathrm{H}_{2} \mathrm{O}$ (o.5M, $\left.0.5 \mathrm{~mL}\right)$, open air, $25^{\circ} \mathrm{C}$, 4 h. Isolated yields. ${ }^{a}$ $\mathrm{H}_{2} \mathrm{O} / \mathrm{THF}$ 1:1 (o.5M) was used as the solvent.

The mechanism of the reaction could take place in two stages. The first step is the hydrocarboxylation of the allene with the TFA, leading to the formation of the corresponding allylic ester (observed in both ${ }^{1} \mathrm{H}$ and ${ }^{19} \mathrm{~F}$ NMR), which is in presence of water in equilibrium with the corresponding iminium/carbocation forms (observed in HRMS ESI+). The second step could be either a nucleophilic substitution on the ester by the sulfinate, with the trifluoroacetate as a leaving group, or either a conjugated addition of the sulfinate to the iminium species, which finally leads to the formation of the desired allylic sulfone. The nucleophilic addition occurred on the $\beta$ position of the iminium salt, which is a classical pathway to obtain enamines. (Scheme 4, A.). ${ }^{26}$ When the reaction was performed using $\mathrm{D}_{2} \mathrm{O}$ as a solvent, while in the presence of TFA or deuterated TFA, 90\% deuterium incorporation was observed at the central position of the allene, which is consistent with the mechanism proposed above. By using benzenesulfinic acid $\left(\mathrm{PhSO}_{2} \mathrm{H}\right)$ instead of the corresponding sodium salt $\left(\mathrm{PhSO}_{2} \mathrm{Na}\right)$, no product was formed, suggesting that the sulfinic acid is not strong enough to protonate the $\mathrm{N}$-allenyl derivative. (Scheme 4, B).
Scheme 4. Proposed mechanism and control experiments.

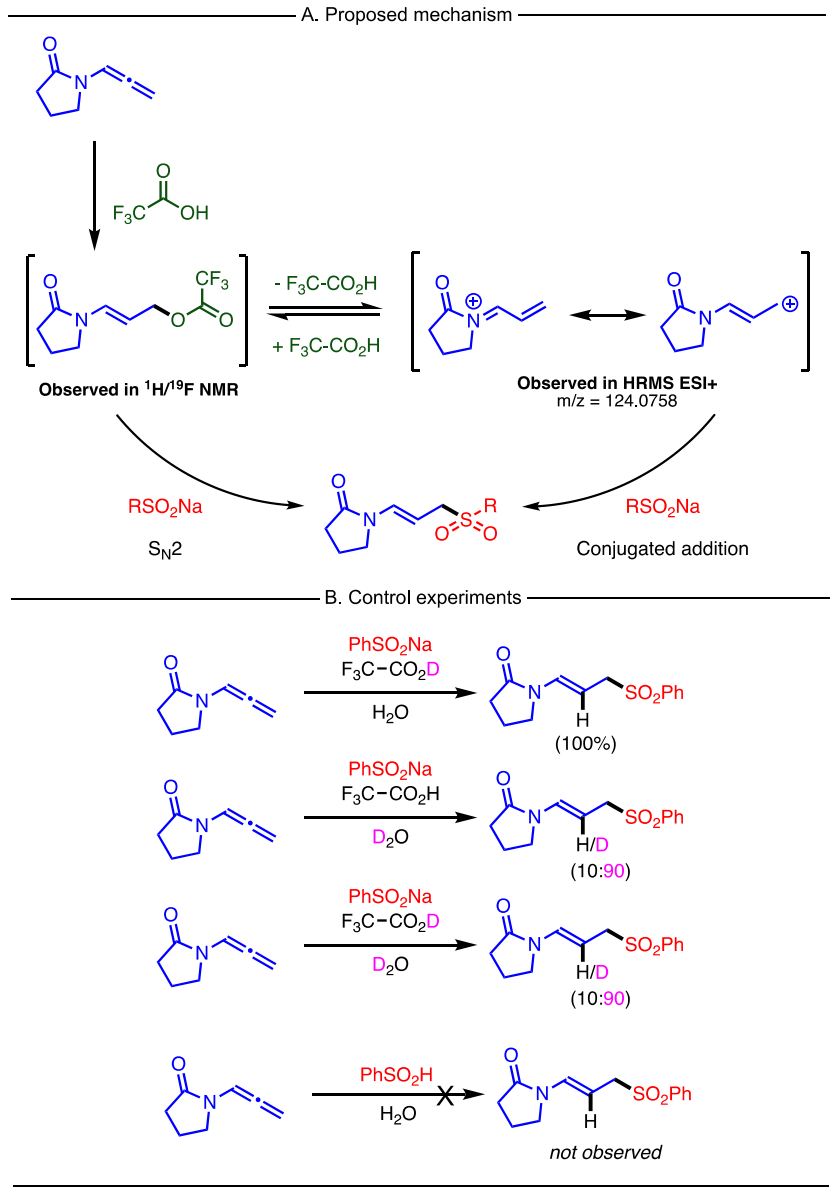

To conclude, we developed a Brønsted acid-mediated allylation of $\mathrm{S}(\mathrm{VI})$-containing nucleophiles. This transition metal-free methodology occurs in mild conditions and allows the hydrosulfonylation of a wide range of $N$ allenyl derivatives substrates with total regio- and stereoselectivity in water. Unprecedented (E)-allylic sulfones and a 1,3-disulfone were obtained with moderate to excellent yields in a total atom economical fashion. Further investigations and mechanistic studies for hydrofunctionalization of allenes will be reported in due course.

\section{ASSOCIATED CONTENT}

\section{Supporting Information}

Detailed experimental procedures and characterization data (NMR ${ }^{~} \mathrm{H},{ }^{13} \mathrm{C},{ }^{19} \mathrm{~F}$, ESI-HRMS and m.p. if solid) for all new compounds are provided in the supporting information (PDF).

The Supporting Information is available free of charge on the ACS Publications website.

\section{AUTHOR INFORMATION}

Corresponding Authors 
* Florian Monnier Institut Charles Gerhardt Montpellier (ICGM), ENSCM, Université de Montpellier, CNRS and Institut Universitaire de France (IUF) ; orcid.org/oooo-ooo29924-2012 ; email : florian.monnier@enscm.fr

* Marc Taillefer Institut Charles Gerhardt Montpellier (ICGM), ENSCM, Université de Montpellier, CNRS ; email : marc.taillefer@enscm.fr

\section{Authors}

Lucas Pagès Institut Charles Gerhardt Montpellier (ICGM), ENSCM, Université de Montpellier, CNRS

Sébastien Lemouzy Institut Charles Gerhardt Montpellier (ICGM), ENSCM, Université de Montpellier, CNRS

\section{Author Contributions}

The manuscript was written through contributions of all authors. / All authors have given approval to the final version of the manuscript.

\section{ACKNOWLEDGMENT}

Financial support was provided by ENSCM (PhD fellowship for LP and postdoctoral fellowship for SL) and CNRS. IUF is warmly acknowledged with thanks.

\section{REFERENCES}

(1) Chen, X.; Hussain, S.; Parveen, S.; Zhang, S.; Yang, Y.; Zhu, C. Sulfonyl Group-Containing Compounds in the Design of Potential Drugs for the Treatment of Diabetes and Its Complications. Curr. Med. Chem. 2012, 19 (21), 3578-3604. https://doi.org/10.2174/o92986712801323225.

(2) Scott, K. A.; Njardarson, J. T. Analysis of US FDA-Approved Drugs Containing Sulfur Atoms. Top. Curr. Chem. 2018, 376 (1), 5. https://doi.org/10.1007/s41061-018-0184-5.

(3) El-Awa, A.; Noshi, M. N.; Jourdin, X. M. Du; Fuchs, P. L. Evolving Organic Synthesis Fostered by the Pluripotent Phenylsulfone Moiety. Chem. Rev. 2009, 109 (12), 69206921. https://doi.org/10.1021/cr9oo248v.

(4) Alba, A. N. R.; Companyó, X.; Rios, R. Sulfones: New Reagents in Organocatalysis. Chem. Soc. Rev. 2010, 39 (6), 2018-2033. https://doi.org/10.1039/b911852g.

(5) Back, T. G.; Clary, K. N.; Gao, D. Cycloadditions and Cyclizations of Acetylenic, Allenic, and Conjugated Dienyl Sulfones. Chem. Rev. 2010, 110 (8), 4498-4553. https://doi.org/10.1021/cr1000546.

(6) Buynak, J. D.; Doppalapudi, V. R.; Rao, A. S.; Nidamarthy, S. D.; Adam, G. The Synthesis and Evaluation of 2Substituted-7-(Alkylidene)Cephalosporin Sulfones as $\beta$ Lactamase Inhibitors. Bioorganic Med. Chem. Lett. 200o, 10 (9), 847-851. https://doi.org/10.1016/So96o-894X(oo)ooo94-

(7) Reck, F.; Zhou, F.; Girardot, M.; Kern, G.; Eyermann, C. J.; Hales, N. J.; Ramsay, R. R.; Gravestock, M. B. Identification of 4-Substituted 1,2,3-Triazoles as Novel Oxazolidinone Antibacterial Agents with Reduced Activity against Monoamine Oxidase A. J. Med. Chem. 2005, 48 (2), 499506. https://doi.org/10.1021/jmo400810.

(8) Nielsen, M.; Jacobsen, C. B.; Holub, N.; Paixão, M. W.; Jørgensen, K. A. Asymmetric Organocatalysis with Sulfones. Angew. Chemie - Int. Ed. 2010, 49 (15), 2668-2679. https://doi.org/10.1002/anie.200906340.

(9) Trost, B. M.; Kalnmals, C. A. Sulfones as Chemical Chameleons: Versatile Synthetic Equivalents of SmallMolecule Synthons. Chem. - A Eur. J. 2019, 25 (48), 1119311213. https://doi.org/10.1002/chem.201902019. Clayden, J.; Julia, M. Allylic Sulfones as Allyl Anion

Equivalents: Homoallylic Alcohols from Metal Catalysed Reactions of Sulfones with Aldehydes and Ketones. J. Chem. Soc. Chem. Commun. 1994, No. 16, 1905-1906. https://doi.org/10.1039/C39940001905.

Blieck, R.; Taillefer, M.; Monnier, F. Metal-Catalyzed Intermolecular Hydrofunctionalization of Allenes: Easy Access to Allylic Structures via the Selective Formation of C-N, C-C, and C-O Bonds. Chem. Rev. 2020, 120 (24), 1354513598. https://doi.org/10.1021/acs.chemrev.ocoo803. Kamijo, S.; Al-Masum, M.; Yamamoto, Y. Palladium Catalyzed Hydrosulfination of Allenes with Tosylhydrazine Leading to Allylsulfones. Tetrahedron Lett. 1998, 39 (7), 691-694. https://doi.org/10.1016/Soo40-4039(97)10637-2. Khakyzadeh, V.; Wang, Y. H.; Breit, B. Rhodium-Catalyzed Addition of Sulfonyl Hydrazides to Allenes: Regioselective Synthesis of Branched Allylic Sulfones. Chem. Commun. 2017, 53 (36), 4966-4968. https://doi.org/10.1039/c7cco2375h.

Pritzius, A. B.; Breit, B. Asymmetric Rhodium-Catalyzed Addition of Thiols to Allenes: Synthesis of Branched Allylic Thioethers and Sulfones. Angew. Chemie - Int. Ed. 2015, 54 (10), 3121-3125. https://doi.org/10.1002/anie.201411402.

Miao, M.; Luo, Y.; Xu, H.; Chen, Z.; Xu, J.; Ren, H. SolventControlled, Tunable Hydrosulfonylation of 3-

Cyclopropylideneprop-2-En-1-Ones. Org. Lett. 2016, 18 (17), 4292-4295. https://doi.org/10.1021/acs.orglett.6bo2047. Goh, J.; Maraswami, M.; Loh, T.-P. Synthesis of Vinylic Sulfones in Aqueous Media. Org. Lett. 2021. https://doi.org/10.1021/acs.orglett.oc04257.

Liu, Y.; Xie, P.; Sun, Z.; Wo, X.; Gao, C.; Fu, W.; Loh, T.-P. Direct Substitution of Secondary and Tertiary Alcohols To Generate Sulfones under Catalyst- and Additive-Free Conditions. Org. Lett. 2018, 20 (17), 5353-5356. https://doi.org/10.1021/acs.orglett.8bo2188.

Blieck, R.; Lemouzy, S.; Taillefer, M.; Monnier, F. Regio-, Stereo- and Enantioselective $\alpha$-Addition of Carbonyl Nucleophiles to Allenamides Catalyzed by a Synergistic Copper/Enamine System. 2020.

https://doi.org/10.26434/chemrxiv.11830935.v3. Abed Ali Abdine, R.; Pagès, L.; Taillefer, M.; Monnier, F. Hydroarylation of N-Allenyl Derivatives Catalyzed by Copper. European J. Org. Chem. 2020, 2020 (48), 74667469. https://doi.org/10.1002/ejoc.202001333. Blieck, R.; Abed Ali Abdine, R.; Taillefer, M.; Monnier, F. Regio- and Stereoselective Copper-Catalyzed Allylation of 1,3-Dicarbonyl Compounds with Terminal Allenes. Org. Lett. 2018, 20 (8), 2232-2235. https://doi.org/10.1021/acs.orglett.8boo575. Blieck, R.; Bahri, J.; Taillefer, M.; Monnier, F. CopperCatalyzed Hydroamination of Terminal Allenes. Org. Lett. 2016, 18 (6), 1482-1485. https://doi.org/10.1021/acs.orglett.6boo452.

Perego, L. A.; Blieck, R.; Groué, A.; Monnier, F.; Taillefer, M.; Ciofini, I.; Grimaud, L. Copper-Catalyzed Hydroamination of Allenes: From Mechanistic Understanding to Methodology Development. ACS Catal. 2017, 7 (7), 4253-4264.

https://doi.org/10.1021/acscatal.7boog11.

Perego, L. A.; Blieck, R.; Michel, J.; Ciofini, I.; Grimaud, L.; Taillefer, M.; Monnier, F. Copper-Catalyzed Hydroamination of N-Allenylazoles: Access to AminoSubstituted N-Vinylazoles. Adv. Synth. Catal. 2017, 359 (24), 4388-4392. https://doi.org/10.1002/adsc.201700965. Blieck, R.; Perego, L. A.; Ciofini, I.; Grimaud, L.; Taillefer, M.; Monnier, F. Copper-Catalysed Hydroamination of NAllenylsulfonamides: The Key Role of Ancillary Coordinating Groups. Synthesis 2019, 51 (5), 1225-1234. https://doi.org/10.1055/s-0037-1611673.

Blieck, R.; Taillefer, M.; Monnier, F. Copper-Catalyzed Hydrocarboxylation of N-Allenyl Derivatives. J. Org. Chem. 2019, 84 (17), 11247-11252. https://doi.org/10.1021/acs.joc.9bo1510. 
(26) Lakhdar, S.; Tokuyasu, T.; Mayr, H. Electrophilic Reactivities of $\alpha, \beta$-Unsaturated Iminium Ions. Angew.

Chemie - Int. Ed. 2008, 47 (45), 8723-8726.

https://doi.org/10.1002/anie.200802889. 